\title{
50 years since citizenship: successes and challenges in Indigenous health
}

\author{
Sandra J Eades ${ }^{\mathrm{a}, \mathrm{d}, \mathrm{e}}$ and Emily Banks $\mathrm{b,c, \textrm {d }}$ \\ a Baker Heart and Diabetes Institute, Melbourne, Vic, Australia \\ b National Centre for Epidemiology and Population Health, Australian National University, Canberra, ACT \\ c Sax Institute, Sydney, NSW, Australia \\ d Guest Editor, Issue 4, 2017 \\ e Corresponding author: sandra.eades@baker.edu.au
}

\section{Article history}

Publication date: October 2017 Citation: Eades SJ, Banks E. 50 years since citizenship: successes and challenges in Indigenous health. Public Health Res Pract. 2017;27(4):e2741730. https://doi.org/10.17061/phrp2741730
In 2017, it is important that we reflect on progress in improving Indigenous health outcomes. We mark the passing of 50 years since Australians voted by an overwhelming majority to amend the constitution to allow the national government to create laws for Indigenous people and include them in the census. The words of the Honourable Ken Wyatt, who reflects on his 45 years of service in health and education and as the current Minister for Indigenous Health, remind us of the important place that Indigenous leaders have played in fostering change in the past. As in the past, leadership from Indigenous people will be key to future progress in Indigenous health. Indigenous leadership was notable in the establishment of Aboriginal community controlled primary health care services, from humble beginnings in Redfern and Perth to the advent of new partnerships in research arising from a National Health and Medical Research Council meeting focused on Aboriginal health in Alice Springs in the mid-1980s. Wyatt highlights the change in Alice Springs with a realisation that Aboriginal people were no longer satisfied with being passive recipients, and instead wanted to be leaders in research that could foster and progress changes and improvements in Indigenous health. Despite all these achievements, Wyatt challenges public health professionals regarding the lack of progress in understanding the social and emotional wellbeing of young Indigenous people, particularly the drivers of suicide and resilience. He also notes the challenges in responding to the needs of ageing Aboriginal Australians, notably in relation to mental health.

In this issue of Public Health Research \& Practice, we review progress on improving Indigenous health with an overview of the Australian Burden of Disease Study of the causes of illness and death in Aboriginal and Torres Strait Islander people. Chronic disease and the impact of modifiable risk factors contribute to $70 \%$ of the gap in the burden of disease among Indigenous Australians compared with non-Indigenous Australians. Between 2003 and 2011, a small 5\% reduction occurred in the overall disease burden, from 454 to 429 disability-adjusted life years per 1000 Indigenous Australians, highlighting the slow but incremental process of improvement. The reduction in burden came mostly from reductions in cardiovascular diseases, infectious diseases, endocrine diseases (including diabetes), gastrointestinal disorders, and infant and congenital conditions. The decrease in total burden was mainly a result of a reduction in the fatal burden (11\%), while the nonfatal burden rose by $4 \%$, because people are living longer with conditions rather 
than dying from them. There is little doubt that the advent of Aboriginal community controlled primary care and increased efforts in targeted health research have contributed to the gains made in the 8 years between the 2003 and the 2011 burden of disease studies. The twin challenges of mental health and substance abuse in younger Indigenous Australians' health outcomes, and cardiovascular disease, cancer and respiratory diseases in older Indigenous Australians' health outcomes, are also discussed in this report.

Other papers in this issue highlight the contributions of Indigenous health research leaders Raymond Lovett and Gail Garvey, and their collaborators. In the tradition of our earlier Indigenous health leaders Naomi Mayers, Pat Delaney and Ted Wilkes, authors Lovett and Garvey draw attention to work being undertaken to stem the Aboriginal and Torres Strait Islander smoking epidemic and foster cancer prevention and early detection. Garvey and collaborators, led by Morris, note the importance of health literacy and culturally appropriate care for Indigenous patients, survivors and families, and highlight these as key research priorities to improve cancer control. Lovett and collaborators describe the stage of the Indigenous smoking epidemic and note that reducing tobacco use requires a continued comprehensive approach to tobacco control, incorporating Indigenous leadership and long-term investment.

All of our efforts in research and policy are of no use if they are not used to improve Indigenous health and implemented by Indigenous health leaders in local communities working in concert with state and territory health departments. The paper by Li and colleagues highlights progress in efforts to expand the Aboriginal population health workforce. The Aboriginal Population Health Training Initiative was established by NSW
Health in 2011 and has successfully trained 17 out of 18 trainees who joined the program. Programs such as this are critical to ensuring a highly skilled population health workforce is available to implement system-wide population health interventions for further Aboriginal health improvement.

This issue of the journal provides an opportunity to reflect on the strength and success of Aboriginal and Torres Strait Islander people in the face of extraordinary adversity, and to consider the next 50 years. It highlights the slow yet incremental process of improvement and what it takes to bring about this progress: leadership, partnership, evidence, respect, and implementation of what is important, right and effective.

We hope readers enjoy these themed papers and all the articles in this issue. Public Health Research \& Practice aims to deliver engaging, high-quality, peerreviewed articles from Australian and international thought leaders, policy makers, practitioners and researchers that will inspire, provoke debate and be useful in your work.

\section{Acknowledgements}

EB is supported by a National Health and Medical Research Council Senior Research Fellowship.

\section{Competing interests}

None declared

\section{Author contributions}

SE and EB both contributed to writing and editing the article.

\section{Copyright: (c)}

(C) 2017 Eades and Banks. This article is licensed under the Creative Commons Attribution-NonCommercial-ShareAlike 4.0 International Licence, which allows others to redistribute, adapt and share this work non-commercially provided they attribute the work and any adapted version of it is distributed under the same Creative Commons licence terms. See: www.creativecommons.org/licenses/by-nc-sa/4.0/ 